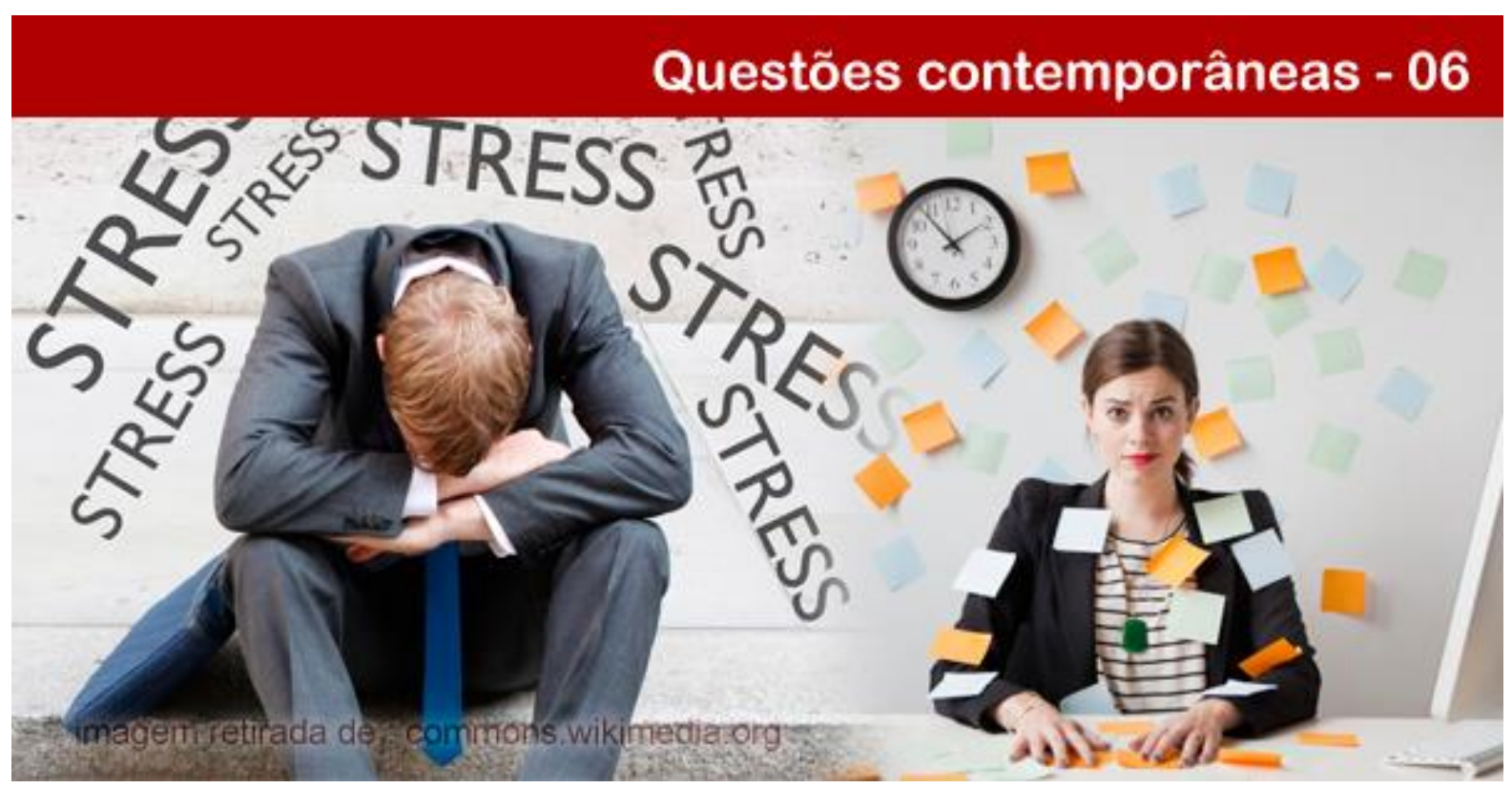

\title{
PROMESSAS DO MUNDO DO TRABALHO CONTEMPORÂNEO E SUAS ARMADILHAS - A ROUPA NOVA DO IMPERADOR EM TEMPOS HIPERMODERNOS
}

\section{Giovana Fagundes Luczinski}

Psicóloga. Mestre em Psicologia Clínica pela Pontifícia Universidade Católica de São Paulo (PUC/SP) e doutoranda em Psicologia Social pela Universidade do Estado do Rio de Janeiro. E-mail: giovana.luczinski@gmail.com.

\section{Ariane Patrícia Ewald}

Professora do curso de Psicologia da Universidade do Estado do Rio de Janeiro, Programa de Pós-Graduação em Psicologia Social.E-mail: arianeuerj@yahoo.com.br.

Resumo: Este artigo empreende uma reflexão crítica sobre o "ideal" de trabalho disseminado na sociedade contemporânea, cujo estilo de vida está pautado no capitalismo flexível como fonte de satisfação profissional, que supostamente traria maior liberdade e autenticidade. Este discurso, fortemente presente na literatura de gestão e em diversos setores da sociedade, vem sendo propagado desde meados dos anos 1970, reforçando o "novo espírito do capitalismo". Apesar da sua força no imaginário social, essas aspirações se tornaram ainda mais difíceis de alcançar na atualidade, por se inserirem em um mercado instável, fruto de uma economia globalizada. Partindo do referencial da Psicologia Social de cunho fenomenológico, com um aporte interdisciplinar, análises críticas sobre o mundo do trabalho são colocadas em diálogo, descortinando ideais, injunções e sintomas que pesam sobre os profissionais. Percebem-se, então, os diversos paradoxos que permeiam a chamada hipermodernidade, nos quais se mostra a outra face do profissional ideal, irreal como o traje do conto A roupa nova do imperador. A contrapartida de um indivíduo flexível, autônomo e multitarefa é um trabalhador angustiado, inseguro de si e da sua função, o qual, na tentativa de realizar o que se espera em um contexto superexigente, coloca em risco sua saúde e sua vida pessoal. Este texto busca evidenciar este processo, pontuando seus custos e a necessidade de desenvolver ações e caminhos para novas formas de se viver e trabalhar.

Palavras-chave: Trabalho. Psicologia. Liberdade. Hipermodernidade.

PROMISES OF THE CONTEMPORARY PROFESSIONAL FIELD AND ITS TRAPS - THE EMPEROR'S NEW CLOTHES IN HYPERMODERN TIMES

\section{POLÊM!CA $\mid$ LABORE (}

Polêmica - Revista Eletrônica da Uerj - Rua São Francisco Xavier, 524, $1^{\circ}$ andar bloco D, sl.1001 • Tels.: +55 21 2334-4088 / 4087 • http://www.e-publicacoes.uerj.br/index.php/polemica/index http://www.labore.uerj.br • laboreuerj@yahoo.com.br 


\begin{abstract}
This article proposes a critical reflection about the "ideal" work widespread in the contemporary society, whose lifestyle is guided by flexible capitalism as a source of professional satisfaction that would supposedly bring greater freedom and authenticity. This speech, strongly present in management literature and in many sectors of society, has been spread since the mid-1970s, reinforcing the "new spirit of capitalism." Despite its force in the social imaginary, nowadays, these desires have become more difficult to achieve inside an instable market, in a global economy. Using the theoretical framework of Phenomenological Social Psychology, with an interdisciplinary support, some critical analysis about the professional world are placed together, in dialogue, revealing ideals, injunctions and symptoms affecting the workers. It shows many paradoxes that permeate the so called hypermodernity, in which appears the other side of the ideal professional, so unreal as the clothes of the history The emperor's new clothes. The other side of a flexible, autonomous, multitasking person is a distressed worker, unsure of himself and his function, who, in an attempt to achieve what is expected in a demanding context, endangers his health and his personal life. This text aims to show this process, punctuating its cost and the need of developing actions and paths towards new ways of living and working.
\end{abstract}

Keywords: Work. Psychology. Freedom. Hypermodernity.

\title{
A roupa nova do imperador: antigas promessas em novas roupagens
}

“- O rei está nú!”. Esta frase, que se tornou emblemática, sintetiza a essência do conto de Hans Christian Andersen ${ }^{1}$, ao qual se faz menção neste subtítulo. O conto, em forma de fábula, quer acentuar a vaidade cortesã e a soberba intelectual que predominam em certos meios sociais, mas pode revelar também, no mundo atual, a forma bastante comum de apresentar como novo o que já é passado, contando sempre com a pretensão de superioridade do que se denomina como "verdadeiramente" novo. "O rei está nú!", pois sua roupa nova, feita por um oportunista, com fios invisíveis que só as pessoas inteligentes e astutas veem, não existe, é um embuste; mas ninguém quer admitir que não vê. Todos querem ser identificados com o ideal de inteligência e esperteza produzido por este suposto alfaiate.

O mesmo tipo de problema parece ser enfrentado no mundo do trabalho atual: todos querem ser identificados com o ideal de profissional criado pelas corporações, mas um olhar atento revela que “O rei está nú!”, mostrando um trabalhador inseguro, angustiado e em profundo sofrimento psíquico.

No início do século XX, Max Weber (2004) já assinalara que as pessoas precisam de fortes razões morais e psicológicas para aderirem ao sistema capitalista que, desde o seu surgimento, se mostra inerentemente contraditório. Em diferentes períodos e contextos, as "razões" que sustentam as adesões têm sido recolocadas, já que os valores mudam, bem como aspirações e sentimentos associados ao trabalho. No final da década de 1990, o notório estudo

\footnotetext{
${ }^{1} \mathrm{Na}$ história, dois tecelões forasteiros se apresentam a um rei vaidoso, prometendo confeccionar, com o mais belo dos tecidos, uma roupa que só pode ser vista por pessoas astutas e hábeis para seus cargos. Ninguém na corte tem a coragem de dizer que não enxerga o traje, nem mesmo o rei, que sai nu em desfile e é denunciado por uma criança na multidão. Mesmo assim, ele segue até o final com seu cortejo, sustentando sua posição.
}

\section{POLÊM!CA $\mid$ LABORE}

Polêmica - Revista Eletrônica da Uerj - Rua São Francisco Xavier, 524, $1^{\circ}$ andar

bloco D, sl.1001 • Tels.: +55 21 2334-4088 / 4087 • http://www.e-publicacoes.uerj.br/index.php/polemica/index

http://www.labore.uerj.br • laboreuerj@yahoo.com.br 
de Boltanski e Chiapello (2009) sobre o "novo espírito do capitalismo" evidenciou as mudanças socioeconômicas que ocorreram na segunda metade do século $\mathrm{XX}$, desencadeando um processo de crescentes insatisfações com as condições de trabalho e normas sociais, gerando novas reivindicações quanto às formas de produzir e viver. Os movimentos de maio de 1968 refletiram essa insatisfação, fazendo uma crítica quanto às condições econômicas vigentes, revendo valores do âmbito cultural e reivindicando maior liberdade, autenticidade, possibilidades de criação e modificação do mundo. A década de 1970, segundo Antunes (1999), tornou-se palco de grandes mudanças culturais, aliadas a transformações políticoeconômicas como o neoliberalismo, a alavancagem dos mercados de ações, a crise do petróleo de 1973, entre outros acontecimentos que provocaram alterações em nível global. Boltanski e Chiapello (2009) assinalam que, nesse momento, o capitalismo acabou se fortalecendo e se flexibilizando em um processo que modificou as estruturas das organizações e o contexto do trabalho. Surgiram novos discursos gerenciais instaurando práticas que levaram o sistema capitalista a se reinventar e se fortalecer a partir das críticas que lhe foram dirigidas. As promessas de maior realização foram fundamentais nesse processo, penetrando no imaginário social do trabalho contemporâneo, conquistando a adesão dos trabalhadores. Os discursos empregados no mundo empresarial, como indicam Boltanski e Chiapello (2009), propagaram as aspirações de liberdade, criatividade e autenticidade, presentes nos desejos mais genuínos das pessoas, prometendo transformá-las em metas realizáveis através da dedicação intensa ao trabalho e do acesso ao consumo. A legitimação dessas demandas reforçou todo um aparato de novas razões para a adesão ao modo de vida veiculado pelo capitalismo, com mudanças qualitativas e quantitativas, que refizeram os pactos relativos ao trabalho no âmbito subjetivo e acabaram fortalecendo o processo de dominação do sistema em curso.

Segundo a pesquisa de Boltanski e Chiapello (2009), nas décadas de 1980 e 1990, as aspirações humanas foram valorizadas, levando a um "neopersonalismo que não enfatiza o sistema, mas os seres humanos em busca de um sentido" (p. 151). Foi dessa forma, segundo estes autores, que as empresas renovaram os pactos de confiança, os modos de parceria e liderança, propiciando um novo tipo de lealdade: sendo leais à sua busca de desenvolvimento, os funcionários investem na sua tarefa, se beneficiam e ajudam a empresa a crescer. Em meio a estes acordos implícitos, o uso de termos impessoais como reengenharia, terceirização, especialização flexível, fusões e franquias, ajudou a tornar as mudanças menos legíveis e mais

\section{POLÊM!CA $\mid$ LABORE}


palatáveis, pois a fluidez das ações modificava as rotinas de trabalho enquanto exaltava os discursos sobre inovação. Como exemplo, pode-se citar o livro de Ricardo Semler, Virando a própria mesa, publicado em 1988, que apresenta exatamente esta visão. Para o autor, o fator "humano" e "justo" se manifestava através da flexibilização de regras e benefícios no universo organizacional, no qual pequenas atitudes relacionadas aos trabalhadores poderiam trazer grandes resultados à empresa como um todo. No entanto, questões estruturais como a distribuição de lucros entre colaboradores, ou questionamentos sobre o sistema, não se definiam como tópicos éticos nesta nova tomada de consciência, refletindo a mentalidade da época.

A análise do sistema capitalista na transição para o século XXI, de acordo com Richard Sennett (2006), mostra que, estruturalmente, pouca coisa mudou quanto ao exercício do trabalho de forma mais livre e criativa, tampouco quanto à diminuição das desigualdades sociais em relação a períodos anteriores. Mesmo com tantas mudanças, as contradições continuam em evidência. Convivem tanto o ranço do pensamento racionalista proveniente do período do Esclarecimento, que valoriza a estabilidade e o progresso, quanto a constatação de sua falácia e a crise de valores que as Artes e as Ciências Humanas denunciam desde o início do século $\mathrm{XX}^{2}$. Entre os estudos recentes sobre o mal-estar na sociedade, alguns pensadores ajudam a pensar o mundo contemporâneo no seu sentido paradoxal, como os sociólogos Berger e Luckmann (2004), bastante conhecidos dos interessados em leituras fenomenológicas. Estes autores assinalam a crise e a desorientação do homem contemporâneo, marcado pelo pluralismo e relativismo, pela expansão tecnológica, intensificação da globalização, ampliação do consumo e do hedonismo. São fenômenos que fazem parte do processo cultural, político e econômico que tem modificado claramente os modos de vida na atualidade. Ao mesmo tempo, apesar das mudanças assinaladas, muitos aspectos característicos do período anterior permanecem, continuando a exercer forte influência nas subjetividades. Como exemplo, pode-se citar a promessa de uma vida cada vez mais confortável, abundante em bens materiais e gradativamente livre de sofrimentos, graças às conquistas da ciência. Esta é, claramente, a visão do Período do Esclarecimento que, norteada por uma ideia de progresso linear, exposta inicialmente por Turgot (1991) e

\footnotetext{
${ }^{2}$ Essa crise foi amplamente discutida por Husserl (2012) e Merleau-Ponty (1973).

\section{POLÊM!CA $\mid$ LABORË}


acentuada por Condorcet (1993), proporcionou uma crença extraordinária no potencial da tecnologia para trazer bem-estar e felicidade às pessoas.

Nas últimas quatro décadas, as aspirações acima foram intensificadas e as promessas foram refeitas com novas roupagens, principalmente no campo do trabalho. A denominação de hipermodernidade para este período, colocada em cena nos estudos de Nicole Aubert (2004), Gilles Lipovetsky e Sébastien Charles (2004), ressalta a intensificação dos valores da modernidade, entrelaçados a novos desejos, de forma paradoxal. A superabundância material dos países desenvolvidos, aliada à expansão do capitalismo financeiro e à evolução tecnológica, foi crucial para consolidar o hiperconsumo, intensificar o individualismo e valorizar o foco na fruição do presente. Surge um tempo de excessos: excesso de consumo, de bens, de demandas, de conceitos e discursos sobre o que traz felicidade, sobre o que se deve ter e como se deve ser. É neste panorama que emerge o indivíduo hipermoderno, assevera Aubert (2004), fruto de uma "modernidade exacerbada" marcada pela intensidade e fluidez, o que o torna completamente diferente daqueles que o precederam. Seduzido pela possibilidade de fruição no presente, de contínuo desfrute do que lhe dá prazer, ele pode trocar promessas antigas por novas, ambíguas e paradoxais, disseminadas agora em todas as áreas do viver, inclusive no mercado de trabalho.

Nesse contexto, é preciso avaliar o que é proposto e o que se ganha de fato, dentro de um movimento que ao primeiro olhar pode parecer natural e inevitável. Para isso, este texto analisa a promessa de liberdade que tem sido refeita aos trabalhadores sob o "novo espírito do capitalismo". Em seguida, propõe um olhar sobre outra promessa do mundo do trabalho, a partir do termo utilizado por Boltanski e Chiapello (2009): a busca de autenticidade. A discussão procura evidenciar os paradoxos e ironias entre aquilo que se promete nos discursos gestionários e aquilo que o profissional vive em seu cotidiano. A outra face do ideal profissional que predomina na sociedade hipermoderna acaba tendo um alto custo pessoal e social, desembocando em adoecimentos e no fortalecimento de um sistema que impõe metas inalcançáveis.

\section{Liberdade: a nova roupa do imperador é "flexível"}

A promessa de maior liberdade para o trabalhador esteve atrelada ao capitalismo nos últimos séculos através da doutrina liberal. O próprio contrato de trabalho supõe em sua base

\section{POLÊM!CA $\mid$ LABORE}


jurídica a livre adesão à proposta de um empreendedor que livremente contrata, gera bens e os vende como acha necessário. Nas últimas décadas do século $\mathrm{XX}$, a intensa demanda por maior liberação, apregoada nos movimentos de maio de 1968, ligou-se ao desejo de maior autonomia e flexibilidade no trabalho. Boltanski e Chiapello (2009) assinalam que as novas ideologias gerenciais fizeram uma aposta inteligente nessa época: de que a promessa de autonomia e liberdade falasse mais alto do que as garantias que o emprego propiciava em períodos anteriores. A proposta funcionou, pois o imediatismo crescente viabilizou a troca da estabilidade pela possibilidade de se fazer uma caminhada profissional que pudesse ser considerada interessante e diferenciada. Este discurso indicava uma desvalorização da estabilidade, algo caro aos trabalhadores anteriormente, mas que passou a remeter a pessoas antiquadas, enrijecidas e pouco empreendedoras. O universo laboral precisou apenas incorporar essa ideia, reforçando aspectos que seriam úteis aos empregadores e sedutores para os trabalhadores.

Nos discursos vigentes, flexibilidade e liberdade passaram a ser colocadas lado a lado, como se a primeira levasse necessariamente à segunda. Ser flexível, hoje, implica a capacidade de estar liberado para experimentar e se movimentar, sendo a disponibilidade para a empresa um ponto amplamente ressaltado, acarretando, por exemplo, viagens e transferências para outras cidades ou países. Os rumos do mercado ditam as oportunidades e exigem que o profissional esteja atento e disposto a abrir mão de seu cargo, ou mesmo da sua profissão, fazendo uma "re-opção" de carreira, se necessário. Assim, cresce a valorização do trabalhador "livre" e "leve", o que pressupõe "renúncia à estabilidade, ao enraizamento, ao apego ao local, à garantia oferecida por elos estabelecidos desde longa data" (BOLTANSKI, CHIAPELLO, 2009, p. 156).

Bauman (2008) também ressalta a valorização da "leveza" por parte dos empregadores, evidenciando o "novo espírito do capitalismo" no mercado americano. Relata a preferência por empregados "descomprometidos", “flexíveis", "generalistas" e "descartáveis": em suma, que tenham um "baixo coeficiente de chateação". Segundo o autor, este termo surgiu a partir de outro, o "chateação zero", que começou a ser usado no final dos anos 90, no Vale do Silício. Vindo do mundo dos esportes, a expressão, que significa "sem atritos" (do original zero drag), indica uma pessoa leve e fluida, que desliza suavemente ao sabor do mercado. Nesse sentido:

\section{POLÊM!CA $\mid$ LABORE}


[...] o empregado ideal seria uma pessoa sem vínculos, compromissos ou ligações emocionais anteriores e que evite estabelecê-los agora; uma pessoa pronta a assumir qualquer tarefa que lhe apareça e preparada para se ajustar e refocalizar de imediato suas próprias inclinações, abraçando novas prioridades e abandonando as adquiridas anteriormente [...] Uma pessoa que também considera as perspectivas de longo prazo, as trajetórias de carreira gravadas na pedra e qualquer tipo de estabilidade mais desconcertantes e assustadoras do que a ausências das mesmas (BAUMAN, 2008, p. 17 e 18).

O profissional que este tipo de mercado procura deve afastar todo o entrave à mobilidade, incluindo vínculos, escolhas e valores que possam ser entendidos como “chateação", por não permitirem uma adesão total ao projeto da empresa. É paradoxal observar que essas demandas requerem um indivíduo para quem o trabalho é o centro da vida, tudo o que realmente importa, mas ao qual não deve se apegar, pois a mudança (de tarefa, de área, de emprego) é sempre uma possibilidade que deve ser "livremente" abraçada. O ganho de competências advindos da sucessão de projetos, supostamente, compensa a instabilidade, que é apresentada como oportunidade de crescimento, já que as redes existentes formam um vasto campo de possibilidades no qual a empregabilidade pode ser "garantida". Este sistema flexível acaba induzindo o profissional a relativizar seus interesses, prejudicando seu senso crítico em relação a demandas dentro e fora do trabalho.

A expansão da tecnologia também transmite a sensação de maior autonomia, pois permite eficiência e mobilidade com o amplo uso de celulares, práticas de home office e videoconferências. No entanto, estes recursos acabam por gerar maior vigilância sobre o trabalhador, além de tornar seu trabalho mais intenso. Buscar a polivalência sem aumento do salário, contratar pessoas superqualificadas, propor cursos e viagens, entre outras ações, são algumas formas de tornar o trabalho mais intenso e produtivo dentro da lógica desse sistema.

Nesse ambiente, os gestores das empresas propagam a crença na capacidade da pessoa de se autogerir, disponibilizando recursos que facilitem essa tarefa. Assim, procuram motivar e promover o envolvimento no trabalho, favorecendo o senso de responsabilidade e autocontrole. A adoção da individualização dos salários, que passam a ser ligados ao desempenho, se torna um eficaz mecanismo de coerção e de produtividade, pois a pessoa se sente responsável também por sua remuneração. Cada um passa a gerir sua própria carreira através da gestão das suas qualidades, sua formação, seu tempo livre, suas opções de consumo e relações interpessoais. Essas demandas exigem um esforço cada vez maior das pessoas, que

\section{POLÊM!CA $\mid$ LABORE}

Polêmica - Revista Eletrônica da Uerj - Rua São Francisco Xavier, 524, $1^{\circ}$ andar

bloco D, sl.1001 • Tels.: +55 21 2334-4088 / 4087 • http://www.e-publicacoes.uerj.br/index.php/polemica/index

http://www.labore.uerj.br • laboreuerj@yahoo.com.br 
são instigadas a "doarem-se" ao trabalho, voluntariamente, cuidando do seu desempenho e da sua formação, de acordo com a proposta dos empresários. Este movimento acaba por consistir em uma "liberdade alienada", expressão utilizada por Fernando Gastal de Castro (2012a, 2012b), cujo referencial teórico está ligado ao pensamento sartriano. Ao aderir a um sistema que promete responder aos anseios de realização individual através de um formato já prescrito, a pessoa acaba delegando a outros suas escolhas e potencialidades. Este processo gera distorções e estranhamentos, pois o profissional imagina ser livre, enquanto internaliza a ordem instituída, abdicando de um posicionamento realmente crítico e original.

As pesquisas de Sennett (2012) com trabalhadores de diferentes gerações nos Estados Unidos indicam que a forma como as mudanças têm acontecido sob o "novo capitalismo" provoca uma fragilização das pessoas, que não se sentem protagonistas na sua própria história. A dificuldade em elaborar uma narrativa pessoal que tenha sentido em um mundo cheio de mudanças contribui para o enfraquecimento dos vínculos e a erosão de qualidades como confiança e lealdade. Essas percepções reforçam as constatações de Castro (2015), quando afirma que as atuais condições de trabalho nas organizações inviabilizam a existência do ser social. As contradições de um mercado hiperexigente desumanizam o trabalho, tornando-o cada vez mais abstrato, irrealizável e individual.

$\mathrm{Na}$ verdade, o tipo de libertação prometido pelo capitalismo revela-se um engodo, pois se assenta sobre um individualismo crescente. Numa discussão sobre a retomada da moral nos tempos atuais e procurando responder à questão título do seu livro O Capitalismo é moral?, André Comte-Sponville (2005) assevera que estamos efetivamente no âmbito do cultivo da esfera privada. É a “era da negligência generalizada" (SPONVILLE, 2005, p. 38), na qual não se faz outra coisa senão negligenciar o outro por uma incapacidade de comungar com quem quer que seja, fragilizando os vínculos sociais. O profissional ideal, agora tão requisitado, é exatamente alguém de quem não se espera vínculos, e, se os têm, são feitos exatamente para cumprir o propósito da produtividade.

A noção de que cada pessoa deve cuidar da própria carreira, sem questionar o sistema, está amplamente disseminada no mundo corporativo. Dessa forma, as conquistas e os ônus ficam a cargo do indivíduo, que deve encontrar o equilíbrio ideal entre trabalho, socialização e cuidado de si dentro de um ambiente altamente mutante, sendo esta uma tarefa interminável. Berger e Luckmann (2004) reforçam que o pluralismo contemporâneo deixou as pessoas mais

\section{POLÊM!CA $\mid$ LABORE}


desorientadas, sem critérios claros para se posicionar em um universo de inúmeras possibilidades e demandas. Ao mesmo tempo, todos são constantemente incentivados a organizar a própria vida, exercendo sua autonomia e liberdade.

Essas reflexões remetem às colocações de Ehrenberg (2012), para o qual a exigência de autonomia passou de aspiração à condição obrigatória da sociedade individualista. Ao se tornar responsável por seu destino e adotar um projeto de excelência, o indivíduo se torna o único culpado por seu fracasso ou sucesso. Dessa forma, as pessoas transitam em uma linha que vai da megalomania à sensação de incapacidade, experimentando sentimentos de impotência, culpa e insuficiência, que podem levar a quadros depressivos. Por ter que exercer a autonomia e a liberdade, a pessoa passa a estar só, vivenciando uma busca contínua de realização. Em suas análises sobre a sociedade da década de 1960, Erich Fromm (1964) já apontava a insegurança como um efeito colateral das conquistas de liberdade, pois novas condições sociais dão margem a novas necessidades e angústias. Estas fazem surgir ideais aos quais as pessoas aderem, cristalizando formas de atuar que se disseminam e passam a influenciar suas ações.

Os comportamentos usuais em relação ao tema da liberdade derivam da noção liberal, predominante na sociedade ocidental, na qual ser livre é entendido como sinônimo de estar sem obstáculos para agir e escolher entre as opções disponíveis. Hannah Arendt (1972) critica essa posição, que considera redutiva, por propagar uma liberdade negativa e privatizada, voltada apenas para evitar coerções e entraves ao existir individual. $\mathrm{O}$ artigo de Castro, Ewald e Mattos (2012) segue na esteira dessa filósofa, considerando a perspectiva liberal um reforço ao individualismo, afastando as pessoas da discussão coletiva sobre as possibilidades concretas de liberdade, que ocorrem nas relações interpessoais cotidianas.

Ao aprofundar o verdadeiro caráter da liberdade, Arendt (2014) afirma que esta não existe sem a coletividade, pois o ser humano é sempre plural, existindo entre outros: semelhantes e diferentes. Por isso, toda liberdade ocorre a partir de ações tecidas entre homens que aceitam o desafio da convivência e do conflito, sendo capazes de transformar o mundo. A pluralidade como condição humana se diferencia do pluralismo enquanto fenômeno contemporâneo. Este surge com o enfraquecimento das metanarrativas, quando as múltiplas vozes e paradigmas culturais que circulam nas sociedades ganham visibilidade. Enquanto este fenômeno cultural pode desorientar algumas pessoas, conforme assinalam Berger e Luckmann

\section{POLÊM!CA $\mid$ LABORE}


(2004), ele também amplia o leque de possibilidades da expressão humana em sua pluralidade. Atualmente, existem inúmeras formas de viver, compreender o mundo e criar, para além das falas hegemônicas veiculadas pela globalização. No entanto, alguns discursos ainda se pretendem universais, abafando as vozes heterogêneas e singulares - como a voz da criança no conto, que expressa a percepção sobre a nudez do imperador.

\section{Autenticidade: o imperador se torna uma metamorfose ambulante}

No final da década de 1960, as demandas por maior liberdade se aliaram àquelas por maior autenticidade, inspiradas por artistas e intelectuais que denunciavam o empobrecimento da vida nas suas diversas esferas, como indicam os trabalhos de Fromm (1964) e Marcuse (1973). Surgiam reivindicações por maior originalidade e diferenciação quanto a produtos e também pessoas, as quais se percebiam uniformizadas pelo pensamento massificador e unidimensional. Autenticidade, nesse contexto, conforme discutida por Boltanski e Chiapello (2009), refere-se à valorização daquilo que expressa a intuição e a criatividade das pessoas, sem possuir uma intenção comercial. Opõe-se à padronização e à produção excessiva de bens materiais, oferecidos através de artimanhas publicitárias, acusadas de promover falsas necessidades e manipular os desejos. No campo interpessoal, as demandas de autenticidade referem-se à busca de encontros mais profundos e genuínos, no lugar da mercantilização das relações.

Campbell (2001) identifica na juventude da década de 1960 um idealismo romantizado, ao supervalorizar a verdade, a espontaneidade e a expressão pessoal, além de criticar o mundo artificial e o conforto. Para o autor, os apelos contidos nesses discursos manifestam expectativas irrealizáveis no cotidiano, tornando-os facilmente cooptáveis pela lógica do capitalismo. Boltanski e Chiapello (2009), denunciam a incorporação dessas questões pelo mercado, que logo passou a oferecer produtos diferenciados para atender à demanda pelo autêntico, além de incluir novos atrativos em esferas como a arte e o turismo. Ao impulsionar o consumo e a produção, este movimento acabou provocando uma sucessão de "ciclos rápidos de entusiasmo e decepção" (BOLTANSKI, CHIAPELLO, 2009, p. 448). Afinal, as mercadorias e serviços ofertados não podiam satisfazer plenamente as altas expectativas, gerando uma satisfação momentânea, seguida de frustração e, posteriormente, motivação para reiniciar o ciclo. Dessa forma, a produção no sistema capitalista mostrou-se

\section{POLÊM!CA $\mid$ LABORE}


inerentemente incapaz de responder às demandas de autenticidade, mas isso se reverteu a seu favor, tornando o desencanto um motor permanente para novas oportunidades de consumo.

Paralelamente à promoção de produtos e serviços no mercado, a demanda por autenticidade impulsionou novos valores nas esferas pessoal e profissional. No âmbito do trabalho, nas últimas décadas, tal exigência esteve presente de forma intensa nos jovens recém-formados, desejosos de desempenhar suas funções de modo próprio e original. Atualmente, o campo profissional é propagado como o lugar por excelência da autoexpressão, no qual cada um pode ser o melhor de si mesmo e se relacionar com outros de forma enriquecedora. Ser autêntico, mostrar um estilo singular e ser reconhecido por suas qualidades se mostram como aspirações dos trabalhadores, que acabam tecendo altas expectativas para suas profissões. "Ser" torna-se o grande objetivo do trabalho e, com isso, os novos discursos gerenciais apostam no "saber-ser", em oposição ao "saber" e ao "saber-fazer" (BOLTANSKI, CHIAPELLO, 2009, p. 131).

Hoje, quanto mais rica em experiências uma pessoa se torna, mais passa a ser admirada pelo mercado. São valorizadas atividades extracurriculares como esportes, viagens, hobbies e voluntariado, que denotam autenticidade. A pessoa passa a ser uma vitrine das suas atitudes, expostas inclusive nas redes sociais, sendo proprietária não apenas de seus bens, seu diploma e seus saberes, mas principalmente da sua imagem, do seu modo de "ser". Surge a prescrição de um ideal, aplicado aos modos de ser profissional, disseminado nos manuais de administração, nos discursos do RH, nas escolas e nos meios de comunicação de massa. A mídia também tem divulgado a importância da imagem, do networking e da capacitação, bem como o conceito de "competência". Este, segundo Gramigna (2007), envolve a preparação para a realização de múltiplas tarefas, com atitudes voltadas para a resolução de problemas, capacidade de aprendizagem constante e boas habilidades interpessoais. O novo profissional deve buscar ser sempre melhor, pois está constantemente à prova, à mercê de processos seletivos que se tornam cada vez mais complexos. Poundstone (2012) apresenta alguns exemplos das novas formas de seleção sob um título provocativo: Você é inteligente o bastante para trabalhar no Google? Ao publicar este "manual de sobrevivência", o autor promete preparar o candidato para uma competição intensa, marcada por entrevistas árduas, nas quais ele precisa mostrar seu valor para fazer parte de uma "companhia hiperseletiva".

\section{POLÊM!CA $\mid$ LABORE}


Quando há um modo prescrito de se comportar, em um sistema que valoriza principalmente a flexibilidade e a capacidade para produzir, a pessoa é reduzida a um padrão, o que se manifesta contrariamente às aspirações de autenticidade que muitos trabalhadores nutrem. Eles se esforçam para serem singulares, investindo em sua formação, mas se perdem entre o ideal disseminado e a precarização crescente das suas condições de trabalho, terminando por aderir ao que se espera deles. Dessa forma, assumem metas de autossuperação que se tornam infinitas, já que propõem o ultrapassamento permanente das conquistas anteriores. O novo modelo de excelência torna provisórios os símbolos tradicionais de sucesso, como diplomas, altos cargos e prêmios, pois estes não garantem os êxitos futuros em uma sociedade mutante e instável. Para Gaulejac (2004), diante da atual exigência de performance, o indivíduo se sente sempre insuficiente, enquanto é "condenado a ter êxito", buscando ilusoriamente ter cada vez mais poder sobre si mesmo e a realidade. Isso o leva a conviver com a possibilidade do fracasso constante, aumentando a sensação de insegurança, a tensão e o esforço para ser mais que um bom profissional. Afinal, ser mediano ou comum não basta: só o super-rendimento parece garantir um lugar no mundo organizacional. Assim, a lógica capitalista do crescimento indefinido atinge a esfera do "ser", sem limites claros a respeito de onde se deva chegar, com multidões aderindo à prescrição que supostamente partiria da autenticidade e levaria ao reconhecimento.

A tarefa de "ser autêntico" acabou se tornando um fardo, por abarcar qualidades inumeráveis, cada vez mais complexas. Analisando o funcionamento da sociedade contemporânea, Ehrenberg (2000) utiliza a expressão "fadiga de ser", mostrando que o cansaço que atinge cada vez mais pessoas acontece em um âmbito mais profundo que o mero excesso de atividades. Uma pesquisa com trabalhadores do setor bancário desenvolvida por Ferreira (2009) deu origem ao livro Perdi um jeito de sorrir que eu tinha, o qual aborda fenômenos de fadiga profunda e adoecimentos no trabalho. O verso de Mário Quintana escolhido para o título da obra expressa a mudança vivida em certos ambientes organizacionais: para se adaptar e sobreviver, a pessoa se mutila, perde um jeito seu de ser e de sorrir, se adequa e se cala, a ponto de não mais se reconhecer.

Para Bendassolli (2006), o desenvolvimento de um falso self tem sido uma das consequências da hostilidade do mundo do trabalho na atualidade. Nada poderia estar mais distante da demanda de autenticidade que emergiu nas décadas passadas. A busca de trabalhos

\section{POLÊM!CA $\mid$ LABORE}


através dos quais as pessoas pudessem ser valorizadas, reconhecidas por suas particularidades, desenvolvendo um estilo próprio, acabou resultando em maior instabilidade no âmbito pessoal. São cada vez mais constantes as trocas de papéis, comportamentos e estilos que são facilmente descartados quando mudam-se as modas ou demandas. Esses fenômenos são parte do funcionamento da sociedade hipermoderna, cuja fluidez e velocidade acarretam dispersão e desengajamento na vida em geral. Segundo a socióloga Claudine Haroche (2008):

São poucos hoje os conhecimentos considerados adquiridos, definitivos; essas condições impedem a possibilidade de um saber cumulativo e provocam a incerteza - muitas vezes radical - em relação a si mesmo e ao outro, abrindo caminho para uma insegurança psíquica profunda (HAROCHE, 2008, p. 185).

Com isso, o sentimento de identidade é prejudicado, pois não se percebe uma continuidade do Eu e sim constantes fragmentações e mutações. Sennett (2006) observa este processo na valorização crescente do ser humano mutante e desprendido no mercado de trabalho, que incentiva as características do "homem-consumidor". Este deveria conseguir manter o foco nas relações de curto prazo, estando disposto a migrar sempre; descobrir e desenvolver novos talentos e capacitações constantemente e ter a habilidade, "como um consumidor ávido", de descartar o passado em busca de algo mais novo e mais moderno.

Nesse contexto acrítico e acelerado, a identidade se torna fluida, metamorfoseando-se de acordo com os ideais veiculados. Evidencia-se aqui estreita relação com o consumo, pois há décadas afirma-se que ao consumir certos itens, a pessoa expressará melhor sua identidade, pois terá um estilo próprio, diferente, original. Muitos acreditam que estão exercendo sua autenticidade, quando, na maioria das vezes, estão se identificando com modelos veiculados no imaginário social, habilmente associados a certos lugares, objetos e ideias. Estilos são adquiridos e descartados, mostrando que o incessante fazer e consumir se amplia para outras esferas da vida, não se restringindo aos bens e serviços. Nas palavras de Slater (2002), na "cultura do consumo": "O eu não é uma percepção interior de autenticidade e sim uma situação calculável de sobrevivência e sucesso social. Temos de produzir e 'vender' uma identidade a vários mercados sociais a fim de ter relações íntimas, posição social, emprego e carreira" (SLATER, 2002, p. 87).

Trata-se de um processo semelhante ao da produção de mercadorias, que são modificadas e ofertadas ao público de acordo com os gostos cambiantes do mercado ao qual

\section{POLÊM!CA $\mid$ LABORE}


se destinam. Nesse sistema, o próprio indivíduo é visto como um ativo gerador de valor, sempre aprimorado e renovado. Este processo passa pela construção da identidade, mas com uma inversão: se antes a pessoa era definida pela atividade que desempenhava, hoje é o ser que agrega valor ao trabalho, tornando-o mais valioso e produtivo. A profissão já não define um lugar no mundo, pois o profissional precisa se reinventar o tempo todo. Este fenômeno traz um grande peso ao indivíduo contemporâneo, que buscou autenticidade aderindo às propostas do mercado e hoje se sente à deriva em relação a si mesmo e ao mundo, como assinala Sennett (2012).

\section{Considerações Finais: o imperador percebe sua exposição}

Este texto buscou evidenciar a existência de um discurso predominante que dissemina um ideal de trabalho calcado na performance, prometendo maior liberdade e autenticidade ao trabalhador, entre outros "ganhos" que não foram possíveis abordar dentro da extensão deste artigo. As reflexões aqui presentes indicam que a "roupa nova do imperador", sustentada pelos desejos e elogios de todos, além de idealizada, contém um avesso complexo. Nas entrelinhas das promessas e demandas que pesam sobre os trabalhadores na sociedade hipermoderna, evidenciam-se fadigas, ansiedades e a escassez de trabalhos livres nos quais as pessoas se sintam autênticas em suas escolhas. Todos querem acreditar no profissional de sucesso que "veste" certas características, as quais o tornam atraente, interessante e superior aos demais. Essa roupagem, criada sob o novo espírito do capitalismo, conquistou inúmeros adeptos nas últimas décadas, principalmente nos discursos gerenciais, ampliando-se para outras esferas.

O profissional hipermoderno se adequa ao mercado de trabalho na medida em que projeta nele a realização de seus desejos e possibilidades de sucesso e consumo, mantendo-se flexível. No entanto, como observa Sennett (2006), as pessoas não parecem mais felizes e realizadas nesse novo contexto, mas sim perdidas, lutando para alcançar um ideal irrealizável para a grande maioria. Aubert (2004) adverte que o "indivíduo hipermoderno" fluido, intenso e mutante não predomina quantitativamente na contemporaneidade. Mídia, empresas e escolas têm propagado como universal um tipo flexível e móvel presente, principalmente, nas classes economicamente mais favorecidas e nos países desenvolvidos. Ao redor do mundo, um enorme contingente de excluídos quer ter acesso ao modo de vida divulgado como rico e

\section{POLÊM!CA $\mid$ LABORE}


estimulante, mas permanece preso a condições de trabalho ainda rígidas e precárias, mais parecidas com o fordismo e o taylorismo do que com a flexibilidade sedutora das grandes corporações. Além disso, o discurso predominante exclui pessoas e movimentos que cultivam diferentes opções e ritmos de vida, originados em ambientes culturais específicos, como o trabalho no campo e o fazer artesanal ou artístico, entre inúmeros arranjos presentes nas diferentes comunidades espalhadas pelo mundo. No entanto, em tempos de globalização, circula a ideia de que todos são hipermodernos e aqueles que não adquirirem as características valorizadas nessa cultura ficarão para trás.

Nas últimas décadas do século XX, intensificaram-se questões já denunciadas anteriormente por pensadores como Arendt (2014) e Marcuse (1973), que alertavam para o perigo de se considerar a sociedade como uma potência que independe dos indivíduos e se sobrepõe a eles. De fato, a origem do engodo organizacional no trabalho, que atropela as pessoas, não está apenas no nível macro. Para que o modelo de profissional aqui explicitado se solidificasse, foi necessário um acúmulo de micromodificações, às quais houve a identificação e adesão dos trabalhadores. Dessa forma, no seu cotidiano, milhares de pessoas têm contribuído para o modo hipermoderno de ser, por se renderem ao seu fascínio, ou por não terem escolha dentro das suas configurações de trabalho. O individualismo, o medo de criar conflitos e a escravização pelo consumo fazem com que as pessoas se calem e seu silêncio se torna também interno, alienante, impedindo o exercício do pensamento, gerando o que Arendt (2002) denomina "atrofia do julgar". Executar as ordens prescritas sem questionálas e sem debater seu sentido, contribui para a perpetuação de práticas prejudiciais. Por isso, reaprender a pensar e a questionar o mundo coletivamente é algo urgente e fundamental na contemporaneidade. Em contextos acríticos, a maioria se força a enxergar a "roupa nova do imperador", adquirindo também uma roupagem irreal para si. No referido conto de Andersen (2010), é uma criança na multidão, ainda não contaminada pelo pensamento predominante, que aponta a falácia do que todos tentam arduamente sustentar. No cotidiano do trabalho das grandes corporações, quem poderá denunciar o engodo das promessas de realização que tem sido refeitas? Torna-se urgente dar atenção às vozes dissonantes que existem em diferentes setores da sociedade.

Segundo Sennett (2012), as pessoas precisam de critérios internos e externos para se afirmarem ou se sentem perdidas e desestabilizadas. Tais critérios não devem ser rígidos,

\section{POLÊM!CA $\mid$ LABORE}


ancorados em metanarrativas dominantes, como em séculos passados, porém, não deveriam ser tão relativos e fluidos que aumentassem a sensação de insegurança, como acontece na contemporaneidade. O campo da Psicologia de base existencial-fenomenológica tem rejeitado concepções de Homem que afirmem características intrínsecas, por remeterem a uma autenticidade idealizada ou a uma unidade rígida do Eu. Nas concepções metafísicas tradicionais, ser autêntico se equiparava a ser uniforme, imutável - conceitos ligados à busca de uma essência interior do indivíduo em oposição à sociedade que o corromperia, distraindoo de si mesmo. Contribuições como as de Arendt $(2002 ; 2014)$ evidenciam a necessidade de romper essa posição sem, no entanto, deixar de afirmar a especificidade da condição humana. Certamente foi um avanço pensar na identidade como metamorfose, substituir a noção de personalidade pela de subjetividade e considerar o ser humano uma obra inacabada, em aberto. Mas é preciso questionar se as novas noções ajudam de fato as pessoas a se reconhecerem como um "Eu" no mundo. $\mathrm{O}$ acesso à experiência pessoal, às próprias percepções e sua confrontação com o contexto ao redor são um exercício necessário para que haja desenvolvimento da pessoa e da sociedade. No entanto, o isolamento crescente acaba por propagar a desconfiança generalizada, levando à perda da noção de codependência, algo fundamental para que um ambiente seja saudável do ponto de vista humano.

A ênfase na autossuficiência torna invisível a dependência necessária nas relações entre os diversos grupos, que precisam de trocas, ajuda mútua e percepções compartilhadas para elaborar a própria trajetória. Se cada pessoa se permitir contatar o mal-estar gerado diante dos paradoxos apresentados cotidianamente, podem surgir novas formas de resistência e de criação na sociedade. Compartilhar as dificuldades pode ser o caminho para que o ideal proposto comece a perder o seu fascínio, evidenciando seus custos e possibilitando decisões mais esclarecidas. Afinal, indivíduo e sociedade se influenciam mutuamente e tudo aquilo que o homem constrói torna-se imediatamente condição de sua existência, como afirma Arendt (2014). Condicionamento e criação, coerção e liberdade são faces da vida concreta na qual os fenômenos surgem e se transformam.

Para além do cenário árido e complexo que aparece no avesso das promessas do mercado de trabalho, aparecem também diversas possibilidades de desconstrução e reinvenção do modelo proposto. Inicialmente, é preciso dar-se conta do processo paradoxal em curso, explicitando seus ganhos e seus custos nos níveis pessoal, social e mesmo

\section{POLÊM!CA $\mid$ LABORE}


ambiental. Para isso, são necessários espaços de convivência que facilitem o contato das pessoas com suas próprias experiências, estranhamentos, dados concretos e desejos. Escolas, famílias e mídia podem promover trocas interpessoais e debates sobre as aspirações profissionais que levem em conta formas alternativas de trabalhar e viver, questionando as noções de sucesso estabelecidas e a qualidade de vida a elas relacionadas. Isso pode acontecer também no ambiente organizacional, quando as pessoas se permitem falar sobre seus incômodos, mesmo que apenas informalmente, reforçando assim suas percepções e fortalecendo ações de enfrentamento. Produções artísticas e intervenções em Psicologia são outros exemplos de ações que podem despertar novos olhares e posicionamentos. Em diferentes cenários, individual e coletivamente, podem-se aproveitar as fissuras do sistema para construir novas formas de trabalho que respeitem as necessidades humanas, reduzindo as insatisfações e os adoecimentos hoje tão frequentes.

O âmbito da Psicologia, do qual partem as reflexões contidas neste artigo, tem potencial para acolher incômodos e facilitar a criação de novos modos de vida e trabalho, em suas diversas modalidades de atuação. No entanto, para que isso aconteça, as intervenções não podem se pautar exclusivamente em análises do âmbito psíquico, ou em visões deterministas sobre o papel da dimensão social. O diálogo com a Sociologia e a Filosofia são fundamentais nesse processo, por integrarem à compreensão psicológica a reflexão sobre aspectos ontológicos, constitutivos do ser humano, bem como o conhecimento sobre os processos políticos e econômicos que interagem com a dinâmica individual. Diante da complexidade do homem, um ser multifacetado, o psicólogo precisa ter consciência das questões que atravessam subjetividade e cultura, as quais se influenciam e transformam mutuamente. Dessa forma, poderá contribuir para que surjam espaços e posicionamentos que ajudem a tecer novas roupagens, com menos desconfortos e paradoxos, além de denunciar os custos e benefícios dos novos ideais profissionais.

\section{Referências}

ANDERSEN, H. C. A roupa nova do imperador. Rio de Janeiro: Zahar, 2010.

ANTUNES, R. L. Os sentidos do trabalho: ensaio sobre a afirmação e a negação do trabalho. São Paulo: Boitempo, 1999.

ARENDT, H. A condição humana. 12a ed. Rio de Janeiro: Forense Universitária, 2014.

\section{POLÊM!CA $\mid$ LABORE}


A vida do espírito: o pensar, o querer, o julgar. Rio de Janeiro: Relume Dumará, 2002.

Entre o passado e o futuro. São Paulo: Perspectiva, 1972.

AUBERT, N. (Org.). L'individu hypermoderne. Sociologie Clinique. Ramonville Saint-Agne: Éditions Érès, 2004.

BAUMAN, Z. Vida para consumo: a transformação das pessoas em mercadoria. Rio de Janeiro: Jorge Zahar Ed., 2008.

BENDASSOLLI, P. F. Os ethos do trabalho - sobre a insegurança ontológica na experiência atual com o trabalho. 2006. 257 p. Tese (Doutorado em Psicologia Social) - Universidade de São Paulo, São Paulo, 2006.

BERGER, P. L.; LUCKMANN, T. Modernidade, pluralismo e crise de sentido - a orientação do homem moderno. Petrópolis, RJ: Vozes, 2004.

BOLTANSKI, L.; CHIAPELLO, E. O novo espírito do capitalismo. São Paulo: Martins Fontes, 2009.

CAMPBELL, C. A ética romântica e o espírito do consumismo moderno. Rio de Janeiro: Rocco, 2001.

CASTRO, F. J. G. Estudos de psicanálise existencial. Curitiba: Editora CRV, 2012a. v.1. $2012 \mathrm{~b}$.

Fracasso do projeto de ser: burnout, existência e paradoxos do trabalho. Rio de Janeiro: Garamond, 2015

Trabalho, exploração e inviabilização do ser social. Revista Intervalo, Lisboa, v. 7, p. 35-48, ago.

CASTRO, F. J. G.; EWALD, A. P.; MATOS, A. Liberdade, alienação e criação literária: reflexões sobre o homem contemporâneo a partir do existencialismo sartriano. Estudos e Pesquisas em Psicologia (Online), v. 12, p. 724-766, 2012.

COMTE-SPONVILLE, A. O Capitalismo é Moral? São Paulo: Martins Fontes, 2005.

CONDORCET, J. A. N. C. M. de. Esboço de quadro histórico dos progressos do espírito humano.

Campinas: UNICAMP, 1993.

EHRENBERG, A. La Société du malaise. Paris: Odile Jacob, 2012.

La Fatigue d'être soi. Dépression et société. Paris: Odile Jacob, 2000.

FERREIRA, J. B. Perdi um jeito de sorrir que eu tinha: violência, assédio moral e servidão voluntária no trabalho. Rio de Janeiro: 7Letras, 2009.

FROMM, E. O medo à liberdade. Rio de Janeiro: Zahar Editores, 1964

GAULEJAC, V. Le sujet manqué. In: AUBERT, Nicole (Org.) L'individu hypermoderne. Sociologie Clinique. Ramonville Saint-Agne: Éditions Érès, 2004.

GRAMIGNA, M. R. Modelo de competências e gestão de talentos. São Paulo: Pearson Prentice Hall, 2007.

HAROCHE, C. A condição sensível: formas e maneiras de sentir no ocidente. Rio de Janeiro: Contra Capa, 2008.

HUSSERL, E. A crise das ciências europeias e a fenomenologia transcendental. Rio de Janeiro: Forense Universitária, 2012.

\section{POLÊM!CA $\mid$ LABORE}

Polêmica - Revista Eletrônica da Uerj - Rua São Francisco Xavier, 524, $1^{\circ}$ andar

bloco D, sl.1001 • Tels.: +55 21 2334-4088 / 4087 • http://www.e-publicacoes.uerj.br/index.php/polemica/index http://www.labore.uerj.br • laboreuerj@yahoo.com.br 
LIPOVETSKY, G.; CHARLES, S. Os tempos hipermodernos. Tradução Mário Vilela. São Paulo: Editora Barcarolla, 2004.

MARCUSE, H. A ideologia da sociedade industrial. Rio de Janeiro: Zahar, 1973.

MERLEAU-PONTY, M. Ciências do Homem e Fenomenologia. São Paulo: Saraiva, 1973.

POUNDSTONE, W. Você é inteligente o bastante para trabalhar no Google? Rio de Janeiro: Zahar, 2012.

SLATER, D. Cultura do consumo \& modernidade. São Paulo: Nobel, 2002.

SEMLER. R. Virando a própria mesa. São Paulo: Best Seller, 1988.

SENNETT, R. A corrosão do caráter. Rio de Janeiro: Best Bolso, 2012.

A cultura do novo capitalismo. Rio de Janeiro: Record, 2006.

TURGOT, A. R. J. Discursos sobre el progresso humano. Madrid: Tecnos, 1991.

WEBER, M. A ética protestante e o "espírito" do capitalismo. São Paulo: Companhia das Letras, 2004.

Recebido em: 23/03/2016.

Aceito em: 30/06/2016.

\section{POLÊM!CA $\mid$ LABORE}

